\title{
Diabetes and diabetes-associated lipid abnormalities have distinct effects on initiation and progression of atherosclerotic lesions
}

\author{
Catherine B. Renard, ${ }^{1}$ Farah Kramer, ${ }^{1}$ Fredrik Johansson, ${ }^{1}$ Najib Lamharzi, ${ }^{1}$ Lisa R. Tannock, ${ }^{2}$ \\ Matthias G. von Herrath, ${ }^{3}$ Alan Chait, ${ }^{2}$ and Karin E. Bornfeldt ${ }^{1}$ \\ 1Department of Pathology and 2Department of Medicine, University of Washington, Seattle, Washington, USA. \\ ${ }^{3}$ La Jolla Institute for Allergy and Immunology, San Diego, California, USA.
}

\begin{abstract}
Diabetes in humans accelerates cardiovascular disease caused by atherosclerosis. The relative contributions of hyperglycemia and dyslipidemia to atherosclerosis in patients with diabetes are not clear, largely because there is a lack of suitable animal models. We therefore have developed a transgenic mouse model that closely mimics atherosclerosis in humans with type 1 diabetes by breeding low-density lipoprotein receptor-deficient mice with transgenic mice in which type 1 diabetes can be induced at will. These mice express a viral protein under control of the insulin promoter and, when infected by the virus, develop an autoimmune attack on the insulin-producing $\beta$ cells and subsequently develop type 1 diabetes. When these mice are fed a cholesterol-free diet, diabetes, in the absence of associated lipid abnormalities, causes both accelerated lesion initiation and increased arterial macrophage accumulation. When diabetic mice are fed cholesterol-rich diets, on the other hand, they develop severe hypertriglyceridemia and advanced lesions, characterized by extensive intralesional hemorrhage. This progression to advanced lesions is largely dependent on diabetes-induced dyslipidemia, because hyperlipidemic diabetic and nondiabetic mice with similar plasma cholesterol levels show a similar extent of atherosclerosis. Thus, diabetes and diabetes-associated lipid abnormalities have distinct effects on initiation and progression of atherosclerotic lesions.
\end{abstract}

\section{Introduction}

People with diabetes have a 2- to 4-fold greater risk than do nondiabetic individuals of developing atherosclerosis and its complications, which include stroke, myocardial infarction, and peripheral vascular disease (1). Several conditions have been proposed to explain the acceleration of atherosclerosis in diabetes, including hyperglycemia, accelerated formation of advanced glycation endproducts (AGEs), increased oxidative stress, hypertriglyceridemia, a high LDL/HDL ratio, hyperinsulinemia, and genetic variables. The Diabetes Control and Complications Trial (2) indicates that a tight control of glucose levels does not substantially reduce cardiovascular events in patients with type 1 diabetes, although very few events were observed in that study.

Since atherosclerosis in diabetic patients is a complex multifactorial disease, suitable animal models would help to identify the cellular and molecular mechanisms involved. In available animal models, toxins such as streptozotocin or alloxan are used to achieve $\beta$ cell destruction and type 1 -like diabetes. However, the action of these toxins is not restricted to $\beta$ cells. Therefore, we took advantage of a transgenic mouse model that develops type 1 diabetes through a process very similar to that of humans, the rat insulin promoter-lymphocytic choriomeningitis virus mouse (RIP-LCMV mouse) $(3,4)$. These mice express the viral glycoprotein (GP) as a self antigen under the control of the RIP. After infection with

Nonstandard abbreviations used: AGE, advanced glycation end-product; BCA, brachiocephalic artery; FPLC, fast-phase liquid chromatography; GP, glycoprotein; LCMV, lymphocytic choriomeningitis virus; LDLR, LDL receptor; NEFA, nonesterified fatty acid; RIP, rat insulin promoter.

Conflict of interest: The authors have declared that no conflict of interest exists.

Citation for this article: J. Clin. Invest. 114:659-668 (2004)

doi:10.1172/JCI200417867.
LCMV, an immune reaction specifically destroys the GP-expressing $\beta$ cells, and mice rapidly develop type 1 diabetes (5). These mice were bred with LDL receptor-deficient (LDLR-deficient) mice, which develop atherosclerotic lesions with morphological characteristics similar to human lesions (6).

The results show that in transgenic $L D L R^{-/-} ; G P$ mice, diabetic dyslipidemia is not required to induce arterial inflammation and lesion initiation, but is associated with development of advanced lesions.

\section{Results}

Diabetic mice show elevated blood glucose and glycated hemoglobin levels. LCMV injection resulted in stable diabetes, which is defined as blood glucose levels greater than $13.9 \mathrm{mmol} / \mathrm{l}(250 \mathrm{mg} / \mathrm{dl})$ in $90 \%$ of mice expressing the GP transgene but never in mice lacking GP. At the end of the study, the body weights of the diabetic mice were slightly lower than those of nondiabetic mice (5-13\% lower), but all diabetic mice had gained weight during the course of the study (Table 1).

Blood glucose levels had increased by $1-2$ weeks after LCMV injection and remained significantly elevated throughout the study in diabetic mice fed the different diets (Figure 1). Mean blood glucose levels and glycated hemoglobin levels were more than 2-fold higher in diabetic than in nondiabetic mice (Table 1).

One group of diabetic mice fed the cholesterol-free diet was treated intensely with insulin to achieve improved metabolic control (Figure 1; Table 1). Blood glucose levels in these mice were not significantly different from those of nondiabetic mice.

Diabetic mice demonstrate loss of endogenous insulin and insulitis. Cross sections of the pancreata from nondiabetic (Figure 2, A and $\mathrm{B}$ ) and diabetic (Figure 2, C and D) mice were analyzed by immunohistochemistry using an anti-insulin antibody. Analysis of the pancreata from diabetic mice indicated a severe destruction 
of $\beta$ cells and loss of immunoreactive insulin (Figure 2, C and D) compared with pancreata from nondiabetic mice (Figure 2, A and B). H\&E staining also revealed insulitis, with characteristic infiltration of $\mathrm{T}$ cells (5) into remaining insulin-positive islets (Figure $2 \mathrm{C}$ ). The number of insulin-positive islets per pancreatic cross section was 7 -fold lower in diabetic mice than in nondiabetic mice $(41.5 \pm 3.6$ islets per cross section in nondiabetic mice and $6.1 \pm 2.0$ islets per cross section in diabetic mice; $P<0.0001$ ). There were no differences in the number of islets among diabetic mice fed the different diets (data not shown).

Nonfasting insulin levels varied between 40 and $295 \mathrm{pmol} / \mathrm{l}$ in nondiabetic mice, between 18 and $332 \mathrm{pmol} / 1$ in insulin-treated diabetic mice, and between 79 and 296 $\mathrm{pmol} / \mathrm{l}$ in intensely insulin-treated diabetic mice (Table 1). Diabetic mice that showed insulin levels in the high range $(<100 \mathrm{pmol} / \mathrm{l})$ generally had received new insulin pellets less than 2 weeks prior to the end of the study. Endogenous insulin levels in diabetic mice that had not received exogenous insulin during the last 2 months were as low as $23.4 \pm 2.3$ $\mathrm{pmol} / \mathrm{l}($ mean $\pm \mathrm{SEM}, n=4)$.

Diabetic mice fed a cholesterol-free diet show no lipid abnormalities. Nondiabetic and diabetic $L D L R^{-/-} ; G P$ mice fed the cholesterol-free diet had similar triglyceride and cholesterol levels (Table 1). Accordingly, nondiabetic and diabetic mice had similar lipoprotein profiles at the end of the study. Thus, diabetes alone does not induce a lipid disorder when these $L D L R^{-/-}$mice are fed a cholesterol-free diet (Figure $3 \mathrm{~A})$. Furthermore, the susceptibility of $\mathrm{LDL}$ to oxidation by $\mathrm{CuSO}_{4}$ in diabetic mice fed the cholesterol-free diet was not different from that of nondiabetic mice (Figure 3B). When mice were fed the cholesterol-free diet, the intensely insulin-treated group of diabetic mice did not have altered blood cholesterol levels in comparison with diabetic mice fed the same diet, but they did show a small but significant elevation of cholesterol levels in comparison with nondiabetic mice at the end of the study (Table 1).

Diabetic mice fed cholesterol-rich diets show increased VLDL and triglyceride levels. Hyperlipidemia, more severe than that normally seen in $L D L R^{-/-}$ mice, developed when dietary fat and cholesterol contents were increased. Cholesterol levels did not change markedly between 6 and 12 weeks from the start of the study (Table 1), and stable hypercholesterolemia was

\section{Table 1}

reached prior to week 3 in most mice (data not shown). Diabetic mice fed the $0.12 \%$ or the $0.5 \%$ cholesterol diet showed markedly elevated cholesterol and triglyceride levels compared with nondiabetic mice (Table 1). These increases were due entirely to an increase in the levels of VLDL (Figure 3, C and D). Nonesterified fatty acids (NEFAs) also were significantly increased in diabetic as opposed to nondiabetic mice fed the $0.5 \%$ cholesterol diet (Table 1 ).

Diabetes causes more atherosclerotic lesions regardless of diet. Nondiabetic and diabetic $L D L R^{-/-}$;GP mice developed aortic lesions, particularly in the arch and in the thoracic aorta distal to the arch. The diabetic mice that were fed the cholesterol-free diet showed significantly increased atherosclerotic lesion area,

Average weights, blood glucose, glycated hemoglobin, plasma lipid levels, and plasma insulin levels in diabetic and nondiabetic mice

\begin{tabular}{|c|c|c|c|c|c|}
\hline & \multicolumn{5}{|c|}{ Diet 1 (0\% Chol.) } \\
\hline & Nondiabetic & Diabetic & $P$ value & Intense insulin & $P$ value \\
\hline Body weight 0 wk (g) & $18.0 \pm 0.4(14)$ & $18.2 \pm 0.4(12)$ & NS & $19.5 \pm 0.4(11)$ & $<0.05$ \\
\hline Body weight 12 wk (g) & $22.0 \pm 0.6(14)$ & $20.1 \pm 0.5(12)$ & $<0.05$ & $21.8 \pm 0.4(11)$ & NS \\
\hline Blood glucose $(\mathrm{mmol} / \mathrm{l})$ & $8.0 \pm 0.1(14)$ & $20.8 \pm 1.7(12)$ & $<0.001$ & $12.1 \pm 0.7(11)$ & NS \\
\hline Glycated $\mathrm{Hb}(\%)$ & $4.9 \pm 0.2(8)$ & $13.4 \pm 1.3(8)$ & $<0.001$ & ND & ND \\
\hline Chol. 6 wk (mmol/l) & $8.4 \pm 0.4(14)$ & $10.1 \pm 0.5(12)$ & NS & $9.2 \pm 0.7(11)$ & NS \\
\hline Chol. 12 wk (mmol/l) & $7.6 \pm 0.6(14)$ & $8.8 \pm 0.6(12)$ & NS & $11.9 \pm 1.9(11)$ & $<0.05$ \\
\hline Triglycerides $(\mathrm{mmol} / \mathrm{l})$ & $1.7 \pm 0.2(8)$ & $2.1 \pm 0.4(8)$ & NS & ND & ND \\
\hline NEFA (mmol/l) & $0.8 \pm 0.1(8)$ & $1.1 \pm 0.1(8)$ & NS & ND & ND \\
\hline Insulin (pmol/l) & $96 \pm 12(10)$ & $146 \pm 28(9)$ & NS & $156 \pm 21(11)$ & NS \\
\hline \multicolumn{6}{|c|}{ Diet 2 (0.12\% Chol.) } \\
\hline & Nondiabetic & Diabetic & $P$ value & & \\
\hline Body weight 0 wk $(\mathrm{g})$ & $18.6 \pm 0.3(12)$ & $18.4 \pm 0.4(9)$ & NS & & \\
\hline Body weight 12 wk (g) & $25.4 \pm 0.6(12)$ & $22.0 \pm 0.4(9)$ & $<0.001$ & & \\
\hline Blood glucose $(\mathrm{mmol} / \mathrm{l})$ & $8.4 \pm 0.2(12)$ & $18.3 \pm 1.6(9)$ & $<0.001$ & & \\
\hline Glycated $\mathrm{Hb}(\%)$ & $5.1 \pm 0.2(7)$ & $10.9 \pm 1.3(7)$ & $<0.001$ & & \\
\hline Chol. 6 wk (mmol/l) & $14.8 \pm 1.1(12)$ & $24.3 \pm 3.5(9)$ & $<0.01$ & & \\
\hline Chol. 12 wk (mmol/l) & $12.5 \pm 1.1(12)$ & $34.9 \pm 5.6(9)$ & $<0.001$ & & \\
\hline Triglycerides $(\mathrm{mmol} / \mathrm{l})$ & $2.6 \pm 0.5(7)$ & $23.8 \pm 8.9(7)$ & $<0.05$ & & \\
\hline NEFA $(\mathrm{mmol} / \mathrm{l})$ & $1.1 \pm 0.1(7)$ & $1.9 \pm 0.4(7)$ & NS & & \\
\hline \multirow[t]{3}{*}{ Insulin (pmol/l) } & $68 \pm 26(7)$ & $81 \pm 41(7)$ & NS & & \\
\hline & \multicolumn{3}{|c|}{ Diet 3 ( $0.5 \%$ Chol. $)$} & \multicolumn{2}{|c|}{ Diet 4 (1.25\% Chol.) } \\
\hline & Nondiabetic & Diabetic & $P$ value & \multicolumn{2}{|c|}{ Nondiabetic } \\
\hline Body weight 0 wk (g) & $19.4 \pm 0.4(13)$ & $18.5 \pm 0.6(6)$ & NS & \multicolumn{2}{|c|}{$19.0 \pm 0.4(7)$} \\
\hline Body weight 12 wk (g) & $23.6 \pm 0.6(13)$ & $21.0 \pm 0.6(6)$ & $<0.05$ & \multicolumn{2}{|c|}{$25.2 \pm 1.2(7)$} \\
\hline Blood glucose $(\mathrm{mmol} / \mathrm{l})$ & $8.4 \pm 0.1(13)$ & $17.5 \pm 1.6(6)$ & $<0.001$ & \multicolumn{2}{|c|}{$8.1 \pm 0.2(7)$} \\
\hline Glycated $\mathrm{Hb}(\%)$ & $4.7 \pm 0.1(6)$ & $10.1 \pm 1.0(5)$ & $<0.001$ & \multicolumn{2}{|c|}{$4.6 \pm 0.3(7)$} \\
\hline Chol. 6 wk (mmol/l) & $20.0 \pm 1.9(13)$ & $58.2 \pm 12.6(6)$ & $<0.001$ & \multicolumn{2}{|c|}{$28.8 \pm 1.3(7)$} \\
\hline Chol. 12 wk (mmol/l) & $22.5 \pm 2.0(13)$ & $55.0 \pm 10.2(6)$ & $<0.001$ & \multicolumn{2}{|c|}{$21.8 \pm 1.3(7)$} \\
\hline Triglycerides $(\mathrm{mmol} / \mathrm{l})$ & $3.5 \pm 0.7(6)$ & $24.6 \pm 7.9(5)$ & $<0.05$ & \multicolumn{2}{|c|}{$4.1 \pm 0.7(7)$} \\
\hline NEFA $(\mathrm{mmol} / \mathrm{l})$ & $1.2 \pm 0.2(6)$ & $5.5 \pm 0.2(5)$ & $<0.05$ & \multicolumn{2}{|c|}{$1.2 \pm 0.2(7)$} \\
\hline Insulin (pmol/l) & $64 \pm 9(6)$ & $126 \pm 31(5)$ & NS & \multicolumn{2}{|c|}{$152 \pm 58(7)$} \\
\hline
\end{tabular}

Nondiabetic and diabetic female $L D L R^{-/-} ; G P$ mice were fed four different semi-purified diets for 12 weeks. Mean blood glucose at the beginning of the study was $8.1 \pm 0.04 \mathrm{mmol} / \mathrm{l}$. Blood glucose levels are shown as mean values during the 12-week study. Glycated hemoglobin $(\mathrm{Hb})$ and triglycerides were measured using kits from Sigma-Aldrich. Total cholesterol was measured in blood, using strips from Polymer Technology Systems Inc., or in plasma, using a kit from Diagnostic Chemicals Limited. NEFAs were measured by using a kit from Wako Chemicals USA Inc. Free insulin levels were measured using an ultrasensitive mousebovine insulin ELISA (ALPCO Diagnostics). Values are mean \pm SEM. The number of animals per group is indicated within parentheses. Statistical analysis was performed using unpaired $t$ test between nondiabetic and diabetic mice fed the same diet or one-way ANOVA between nondiabetic and diabetic mice fed the cholesterol-free diet 1 and between nondiabetic and diabetic mice intensely treated with insulin. Chol., Cholesterol; NS, nonsignificant; ND, not determined. 


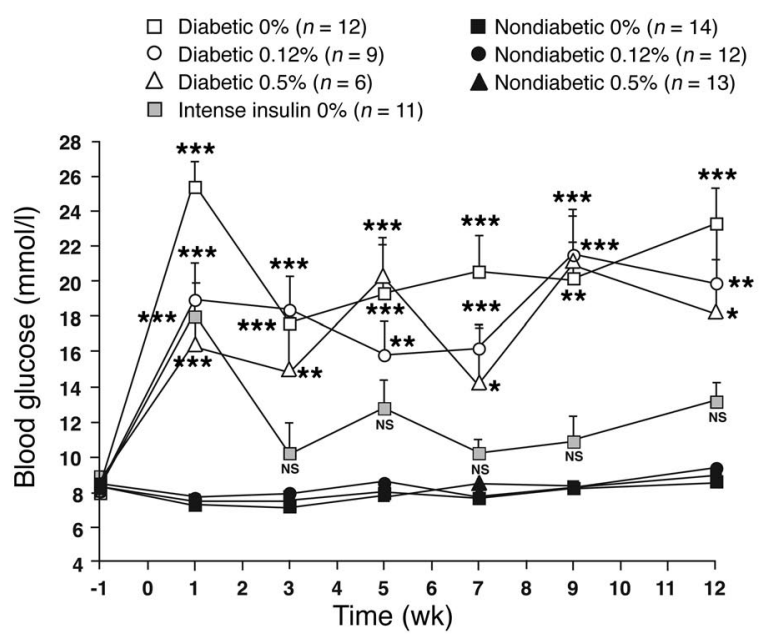

Figure 1

Diabetic mice demonstrated hyperglycemia throughout the study, and their metabolic control was improved by intense insulin therapy. Female $L D L R^{-/-} ; G P$ littermate mice were injected with saline (nondiabetic) or LCMV (diabetic) 1 week prior to changing the diet at week 0 . The diets contained $0 \%, 0.12 \%$, or $0.5 \%$ cholesterol (see key). One group of diabetic mice was treated with an intense insulin therapy (intense insulin) and fed the cholesterol-free diet. Blood glucose was measured at the indicated times. The number of animals per group is indicated within parentheses. NS, nonsignificant versus nondiabetic mice fed the cholesterol-free diet. ${ }^{\star} P<0.05,{ }^{* \star} P<0.01$, ${ }^{\star *}{ }^{*} P<0.001$.

2.8-fold over nondiabetic mice (Figure 4, A and B). Statistical univariate ANOVA showed that this increase could be explained by hyperglycemia (i.e., the increased lesion area was no longer statistically significant when corrected for hyperglycemia; $P>0.05$ ) but not by total cholesterol (corrected $P<0.001$ ). Intense insulin treatment of diabetic mice fed the cholesterol-free diet resulted in normalization of the lesion area (Figure 4, A and B).

Diabetic mice that were fed the $0.12 \%$ and $0.5 \%$ cholesterol diets also showed significantly increased lesion area (2.2-fold and 2.5-fold over nondiabetic mice, respectively) (Figure 4, A and B). In these diabetic mice, the increase could be explained by the increased cholesterol levels (i.e., the increased lesion area was no longer statistically significant when corrected for plasma cholesterol levels; corrected $P>0.05$ ). To further analyze the contribution of hyperglycemia as opposed to that of hyperlipidemia in these mice, subgroups of diabetic and nondiabetic mice with plasma cholesterol levels in the range of $30 \mathrm{mmol} / 1$ were selected for comparison of lesion areas. Diabetic mice were selected from the groups fed the $0.12 \%$ and the $0.5 \%$ cholesterol diets, whereas nondiabetic mice were selected from the groups fed the $0.5 \%$ and the $1.25 \%$ cholesterol diets. The results show that the lesion area in fat-fed nondiabetic and diabetic mice with similar extents of hyperlipidemia was similar (Figure 4C). These results suggest that hyperglycemia has no demonstrable effect on lesion area in the presence of severe hyperlipidemia and that the increased lesion area in diabetic mice fed the cholesterolrich diets is due primarily to the increased cholesterol and triglyceride levels seen in these mice.

LCMV infection in mice lacking the GP transgene does not mimic the effects of diabetes. LCMV-injected control mice lacking the GP transgene showed no differences in lipid levels, glucose levels, or extent of atherosclerosis compared with mice injected with saline.
The lack of effect of LCMV infection was apparent in mice fed the cholesterol-free diet, in mice fed the $1.25 \%$ cholesterol diet (Table 2 ), and in mice fed the $0.12 \%$ or $0.5 \%$ cholesterol diet (data not shown). Thus, the results obtained in diabetic mice are not due to LCMV infection per se.

Diabetic mice fed the cholesterol-free diet show increased lesion initiation, whereas mice fed cholesterol-rich diets show marked intralesional bemorrhage in the brachiocephalic artery. Diabetic mice fed the cholesterol-free diet demonstrated fatty-streak lesions characterized by macrophage infiltration in the brachiocephalic artery (BCA), as shown in Figure 5, A-F, whereas nondiabetic mice had significantly fewer fatty-streak lesions at this site (Figure 5G; Table 3). In addition, diabetic mice had a significantly higher frequency of glycosaminoglycan accumulation in the aortic media compared with nondiabetic mice, as demonstrated by Movat's pentachrome stain (e.g., Figure 5, A and G; Table 3). To investigate possible mechanisms of the increased atherosclerosis in diabetic mice fed the cholesterol-free diet, AGEs were detected by immunohistochemistry. Most of the AGE immunoreactivity was observed in macrophage-rich areas, but some staining was also apparent in smooth muscle cells and in the extracellular tissue surrounding the vessel. No staining was present in the negative rabbit serum control (Figure 5I). Nondiabetic mice fed the cholesterolfree diet exhibited little AGE staining (Figure 5J), whereas diabetic mice showed positive AGE immunoreactivity localized primarily to macrophages (Figure $5 \mathrm{H}$ ).

For mice fed the cholesterol-rich diets, lesion severity was markedly increased by the presence of diabetes. Diabetic mice on the $0.12 \%$ and $0.5 \%$ cholesterol-rich diets consistently exhibited intralesional hemorrhage (Figure 6, A-C), and erythrocytes were present in the lesions (Figure 6B). Conversely, intralesional hemorrhage was seldom found in nondiabetic mice fed cholesterol-rich diets at this 12-week time point (Figure 6D). AGE immunoreactivity was pres-

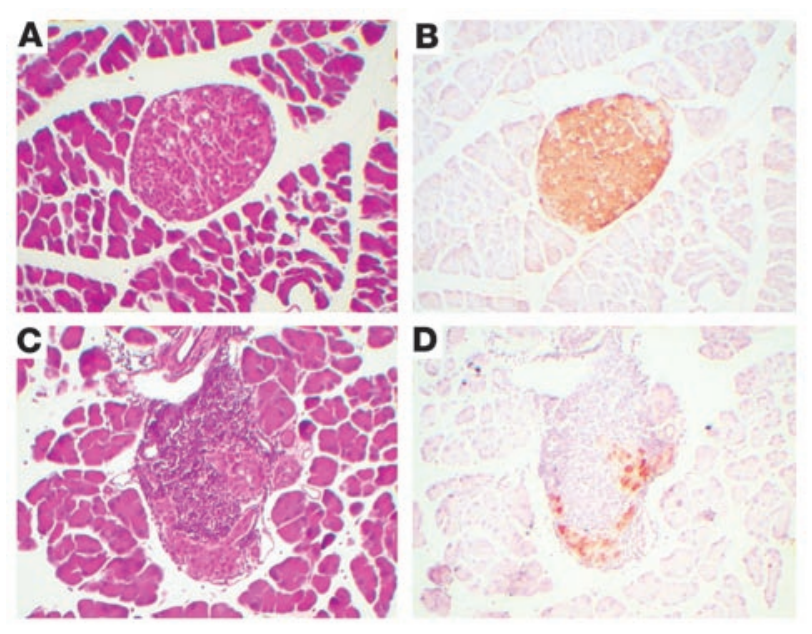

\section{Figure 2}

Diabetic mice exhibited severe insulitis and loss of immunoreactive insulin in $\beta$ cells. Thirteen weeks after LCMV or saline injection, the pancreata of nondiabetic ( $\mathbf{A}$ and $\mathbf{B}$ ) and diabetic ( $\mathbf{C}$ and $\mathbf{D})$ mice were dissected, embedded, cross-sectioned, and stained with H\&E (A and C). Immunoreactive insulin was detected by using a mouse monoclonal anti-insulin antibody in adjacent sections. This procedure results in a brown reaction product (B and $\mathbf{D})$. The procedure was performed on 3-4 mice per group with similar results. 

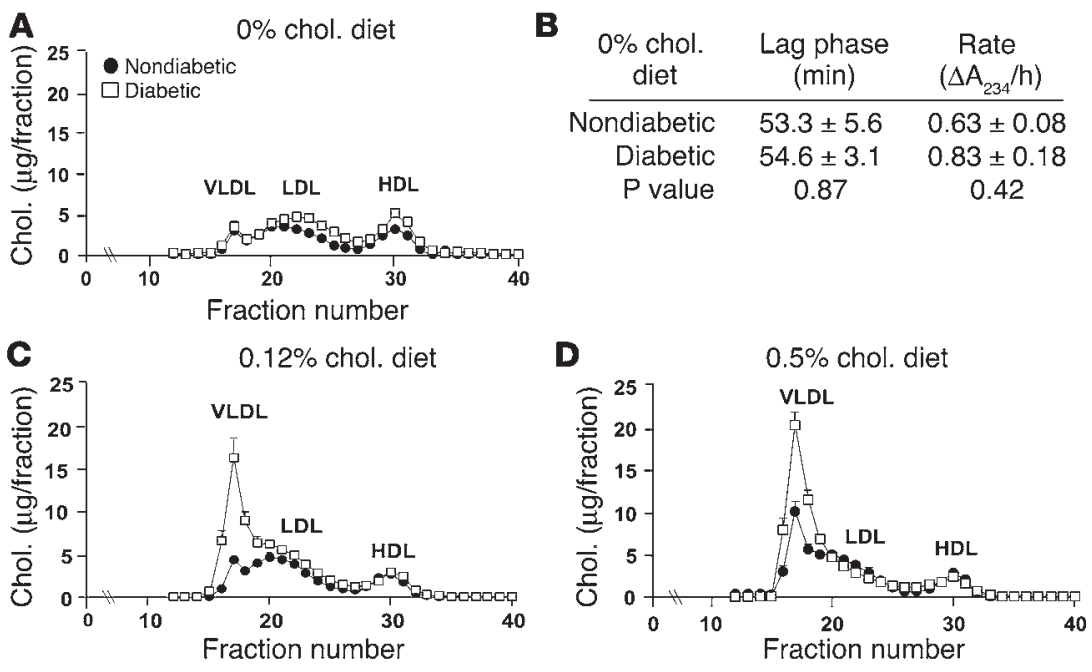

Figure 3

Diabetic mice fed cholesterol-rich diets developed diabetes-associated lipid abnormalities, while diabetic mice fed a cholesterol-free diet had no diabetes-induced lipid abnormalities. Plasma cholesterol profiles of nondiabetic and diabetic mice fed different diets were analyzed by FPLC (A, C, and D). A 100- $\mu$ l aliquot of plasma obtained after 12 weeks on the diet was applied to a column filled with Superose 6HR. Each $250-\mu$ l fraction was subjected to cholesterol analysis. The results are presented as mean + SEM (A, C, and D) and mean \pm SEM (B) of plasma samples obtained from 3 different animals. The major lipoprotein peaks (VLDL, LDL, and HDL) are indicated. Susceptibility of LDL to copper oxidation was measured in LDL fractions isolated from nondiabetic and diabetic mice fed the cholesterol-free diet (B). The appearance (lag phase and rate of formation) of conjugated dienes was measured by a spectrophotometer. Chol., cholesterol.

ent in macrophages in lesions from both diabetic (Figure 6E) and nondiabetic mice (Figure 6F) that were fed cholesterol-rich diets.

To address the question whether diabetic mice that were fed the cholesterol-rich diets exhibited more intralesional hemorrhage regardless of lesion size, the diabetic animals were matched with nondiabetic animals that were fed any of the three cholesterol-rich diets but with the same maximal cross-sectional area of lesions in the BCA (Figure 6G). Diabetic mice with a maximal lesion cross-sectional area of $119,231 \pm 19,497 \mu \mathrm{m}^{2}$ (mean \pm SEM, $n=9$ ) were matched with nondiabetic mice with a maximal lesion cross-sectional area of $114,783 \pm 30,232 \mu \mathrm{m}^{2}$ $(n=9 ; P=0.91)$. In these diabetic mice, hemorrhage covered $60 \% \pm 10 \%$ of the analyzed BCA lesion length but only $12 \% \pm 4 \%(P<0.001)$ of the lesion in nondiabetic mice, as shown graphically in Figure 6G. Therefore, the effect of diabetes on intralesional hemorrhage is not merely a reflection of the larger lesions in diabetic mice but is due to variables within the diabetic milieu.

Notably, diabetic mice fed the high-cholesterol diets showed increased mortality. Whereas $93 \%$ of diabetic mice fed the cholesterol-free diet survived, only $41 \%$ of diabetic mice fed the $0.12 \%$ diet survived, and $33 \%$ of diabetic mice fed the $0.5 \%$ cholesterol diet survived the 12-week study. In contrast, 100\% of the nondiabetic mice survived, regardless of diet. The increased mortality in diabetic mice on these cholesterol-rich diets was not due to increased severity of the diabetic state (e.g., dehydration, hyperglycemia, and/or ketoacidosis). In some of the diabetic fatfed mice that died or (when possible) were euthanized on an emergency basis during the course of the study, advanced lesions with cholesterol clefts were observed in the extension of the aortic sinus into the coronary arteries (Figure 7A), and coronary microvessels almost completely occluded by foam cells were present (Figure 7B). In addition, at least $30 \%$ of these animals showed complete occlusion of arteries (aorta, coronary microvessels, and/or pulmonary microvessels) caused by Sudan IV-positive neutral lipid deposits (Figure 7, C and D). The hearts of some of these diabetic mice also showed interstitial fibrosis, and the kidneys frequently contained microaneurysms (7); such changes are not likely to be fatal, however. No other abnormalities that may have caused death were found in these diabetic mice. The increased mortality in diabetic mice that were fed the cholesterol-rich diets is therefore probably due to occlusion of arteries by lipid embolism and occluding plaques.
A

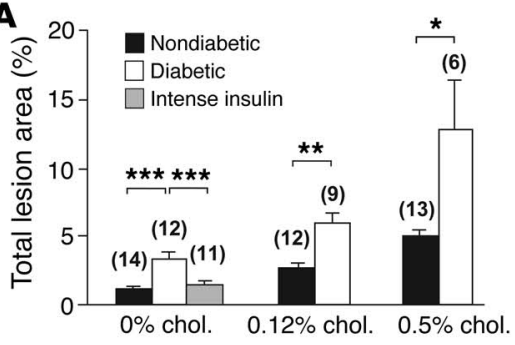

B

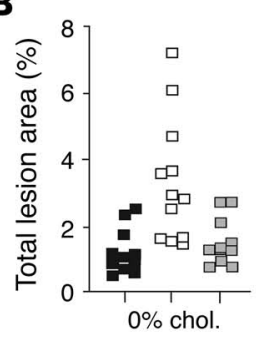

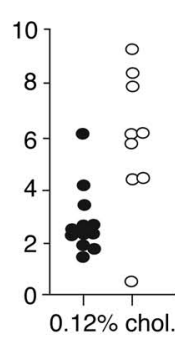

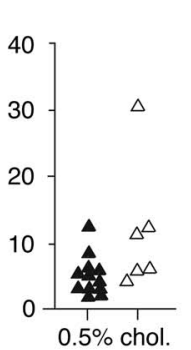

C

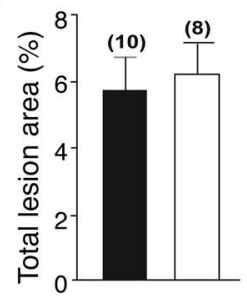

Nondiabetic (matched plasma chol. $27.2 \pm 1.5 \mathrm{mmol} / \mathrm{l}$

Diabetic (matched plasma chol. $29.0 \pm 0.5 \mathrm{mmol} / \mathrm{l}$

Figure 4

Diabetes caused a greater degree of atherosclerosis regardless of dietary cholesterol content (shown as percentage). After 12 weeks on diet, diabetic and nondiabetic $L D L R^{-1-} ; G P$ mice were killed by cardiac perfusion and their tissues fixed. The aorta was dissected, and the area covered by atherosclerotic lesions was identified by Sudan IV staining and image analysis. Results are expressed as mean + SEM (A and C) or as scatter plots (B). In C, subgroups of cholesterol-fed nondiabetic and diabetic mice with similar plasma cholesterol levels were selected for comparison of lesion area. The number of mice per group is indicated above each bar in $\mathbf{A}$ and $\mathbf{C}$. Statistical analysis was performed by using unpaired Student's $t$ test or one-way ANOVA followed by the Newman-Keuls multiple-comparison test $\left({ }^{*} P<0.05,{ }^{* \star} P<0.01\right.$, and ${ }^{* \star *} P<0.001$ for comparison of groups within brackets). Symbols in B are defined in Figure 1. 
Table 2

LCMV infection does not affect levels of glucose, lipids, or atherosclerosis in mice lacking the GPtransgene

\begin{tabular}{lrrrrrr} 
& \multicolumn{3}{c}{ Diet 1 (0\% chol.) } & \multicolumn{2}{c}{ Diet 4 (1.25\% chol.) } \\
& \multicolumn{1}{c}{ Saline } & \multicolumn{1}{c}{ LCMV } & \multicolumn{1}{c}{$\boldsymbol{P}$ value } & \multicolumn{1}{c}{ Saline } & \multicolumn{1}{c}{ LCMV } & P value \\
Body weight (g) & $22.4 \pm 0.8$ & $23.0 \pm 0.7$ & NS & $22.8 \pm 0.5$ & $23.6 \pm 0.7$ & NS \\
Blood glucose (mmol/l) & $8.1 \pm 0.1$ & $9.1 \pm 0.2$ & NS & $8.6 \pm 0.2$ & $8.8 \pm 0.3$ & NS \\
Chol. 12 wk (mmol/l) & $7.8 \pm 0.7$ & $7.2 \pm 0.7$ & NS & $19.0 \pm 0.4$ & $19.7 \pm 1.7$ & NS \\
Triglycerides (mmol/l) & $1.8 \pm 0.2$ & $1.6 \pm 0.3$ & NS & $4.3 \pm 0.5$ & $5.0 \pm 0.5$ & NS \\
Aortic lesion area (\%) & $1.5 \pm 0.2$ & $2.2 \pm 0.6$ & NS & $6.4 \pm 0.6$ & $6.9 \pm 1.1$ & NS \\
\hline
\end{tabular}

Control $L D L R^{-1-}$ mice lacking the GP transgene were injected with LCMV and then fed two different semi-purified diets containing $0 \%$ or $1.25 \%$ cholesterol for 12 weeks. Blood glucose, total cholesterol, and triglycerides were measured as in Table 1. Total aortic area covered by lesions was calculated after Sudan IV staining of the aorta. Values are mean \pm SEM. Groups consisted of 6-8 animals (statistical analysis, unpaired $t$ test). NS, Nonsignificant.

\section{Discussion}

Diabetes in the absence of dyslipidemia secondary to diabetes accelerates arterial inflammation and lesion initiation. The results of this study show that diabetes-associated dyslipidemia is not required to induce arterial inflammation, characterized by macrophage accumulation, and lesion initiation. The effect of dyslipidemia in relation to other conditions associated with diabetes (e.g., hyperglycemia) on lesion initiation has not been addressed previously because of the lack of suitable animal models. In existing models, the effects of diabetesinduced increases in cholesterol, triglyceride, and blood glucose levels have been difficult to separate (8-14). In the $L D L R^{-/-}$;GP model used here, not only is the mechanism of diabetes induction more similar to that in humans than previous models that used the toxins streptozotocin or alloxan, but, importantly, these mice do not develop diabetes-induced lipid abnormalities when fed a cholesterol-free diet. Thus, diabetic mice fed the cholesterol-free diet do not show elevated levels of total cholesterol, triglycerides, or NEFAs as compared with nondiabetic mice fed the same diet, and they exhibit lipoprotein profiles and susceptibility of LDL to oxidation that are similar to those of nondiabetic mice. The increased atherosclerosis in diabetic mice could be normalized by intense insulin treatment, indicating that the accelerated atherosclerosis in diabetic mice is due to conditions associated with the diabetic environment, most likely hyperglycemia. Furthermore, these results argue against an independent effect of transient localized inflammation in the pancreas as a direct cause of the increased atherosclerosis in these diabetic mice. Statistical analysis confirmed that the diabetes-mediated increase in lesion area in mice fed a cholesterol-free diet can be attributed to hyperglycemia. Although we cannot exclude that other variables dependent on or independent of glucose levels, such as oxidative stress or changes in blood pressure, can contribute to the accelerated atherosclerosis in these mice, it is clear that diabetes-induced lipid abnormalities are not necessary for lesion initiation.

In this context it may be important that $L D L R^{-/-}$mice fed chow diets normally exhibit cholesterol levels in the range of 6-9 mmol/1, compared with 3-4 mmol/1 in WT C57BL/6 mice. C57BL/6 mice develop little atherosclerosis even with fat feeding, and streptozotocin-induced diabetes does not lead to more atherosclerosis in these mice (8). Accordingly, heterozygous $L D L R^{+/-}$;GP mice injected with LCMV showed insulitis, were diabetic, and had plasma total cholesterol levels in the range of $3 \mathrm{mmol} / \mathrm{l}$, but had no aortic lesions (data not shown). Thus, it seems that moderately elevated basal cholesterol levels are required for diabetes to induce arterial inflammation and lesion initiation.

How might hyperglycemia induce arterial inflammation? Notably, hyperglycemia in mice fed the cholesterol-free diet resulted in a considerable accumulation of both macrophage foam cells and glycosaminoglycans in the arterial wall. Glycosaminoglycan accumulation was often observed in the absence of infiltrating macrophages, which suggests that this may be one of the first steps in lesion initiation in diabetes. Since glycosaminoglycans are believed to cause retention of lipoproteins in the arterial wall, this process may act to increase macrophage accumulation (15). Furthermore, hyaluronan, a common glycosaminoglycan in arteries, may stimulate macrophage recruitment to lesions. Thus, apolipoprotein E-deficient mice that are also deficient in CD44, a hyaluronan receptor, exhibit reduced atherosclerosis and macrophage recruitment to lesions (16). Diabetic mice fed the cholesterol-free diet also showed immunoreactive AGEs localized to lesion macrophages. Nondiabetic mice fed this diet exhibited

\section{Table 3}

Fatty streaks and glycosaminoglycan accumulation in diabetic mice fed a cholesterol-free diet, and intralesional hemorrhage in the BCA of cholesterol-fed diabetic mice

\begin{tabular}{|c|c|c|c|c|c|c|}
\hline & Fatty streak & Medial GAGs & Fibrous cap & Collagen & Necrotic core & Intralesional hemorrhage \\
\hline \multicolumn{7}{|l|}{ 0\% Chol. diet } \\
\hline Nondiabetic & $0.2(3 / 13)$ & $0.2(2 / 13)$ & $0(0 / 13)$ & $0(0 / 13)$ & $0.1(1 / 13)$ & $0(0 / 13)$ \\
\hline Diabetic & $0.9(11 / 12)^{A}$ & $1.0(12 / 12)^{\mathrm{B}}$ & $0.2(3 / 12)$ & $0.2(3 / 12)$ & $0.4(5 / 12)$ & $0(0 / 12)$ \\
\hline \multicolumn{7}{|l|}{$0.12 \%-1.25 \%$ Chol. diet } \\
\hline Nondiabetic & $0.5(8 / 17)$ & $0.6(11 / 17)$ & $0.5(9 / 17)$ & $0.5(9 / 17)$ & $0.6(10 / 17)$ & $0.2(4 / 17)$ \\
\hline Diabetic & $0.3(4 / 11)$ & $1.0(11 / 11)$ & $0.6(6 / 11)$ & $0.6(6 / 11)$ & $0.8(9 / 11)$ & $0.8(8 / 11)^{\mathrm{C}}$ \\
\hline
\end{tabular}

The BCAs from nondiabetic and diabetic $L D L R^{-/-}$;GP littermates were serial sectioned, starting from the aortic arch to a point where the lesion was maximal (up to $800 \mu \mathrm{m}$ ). Sections from every $20 \mu \mathrm{m}$ were stained using a Movat's pentachrome method. The presence of fatty streak-type lesions, medial glycosaminoglycan (GAG) accumulation, fibrous cap, collagen, necrotic core, and hemorrhage anywhere in the BCAs was scored as 1 . Lack of these characteristics was scored as 0 . The results are shown as the mean score, with the number of positive BCAs out of total BCAs given in parentheses. ${ }^{A} P<0.01$, ${ }^{\mathrm{B} P}<0.001,{ }^{\mathrm{C}} P<0.05$ (Fisher's exact test). 
macrophage infiltration only occasionally, but when macrophages were present, AGE immunoreactivity was also observed, consistent with previous studies (17). AGEs can localize to macrophages as a result of uptake mediated by macrophage scavenger receptors $(18,19)$. Furthermore, AGEs can be formed by processes other than glycation, such as lipid peroxidation (20). It is possible that because of the increased macrophage accumulation in diabetes there is an increased AGE accumulation in lesions, which might contribute to the accelerated atherosclerosis. In addition, hyperglycemia may induce monocyte adhesion molecule expression on the endothelium, as seen in models of streptozotocininduced diabetes and hyperglycemia $(21,22)$.

Thus, hyperglycemia may cause arterial inflammation and early lesions that are not likely to directly cause clinical events; this result is consistent with the lack of effects of improved blood glucose control on cardiovascular events in people with diabetes (2).

Diabetes-induced increases in VLDL levels contribute to the accelerated atherosclerosis and intralesional hemorrhage in mice fed cholesterol-rich diets. In the $L D L R^{-/-}$;GP model, diabetic mice fed cholesterol-rich diets had more atherosclerosis than nondiabetic littermates fed the same diets. The increased lesion area in cholesterol-fed diabetic mice most likely was due to the elevated plasma lipid levels in diabetic mice, because when diabetic mice were matched with nondiabetic mice with similar plasma cholesterol levels, the effect of diabetes on aortic lesion area was lost. Therefore, it is likely that in the presence of severe hyperlipidemia the effects of hyperglycemia on lesion initiation are masked. These findings are consistent with a previous study on streptozotocin-diabetic $L D L R^{-/-}$mice fed a diet containing $0.75 \%$ cholesterol for 6 months, in which diabetes did not induce a difference in lesion area (13). Thus, hyperglycemia is likely to stimulate lesion initiation, whereas diabetes-induced hyperlipidemia drives lesion progression.

In the $L D L R^{-/-}$; GP model, diabetic mice fed cholesterol-rich diets not only had more atherosclerosis but also consistently demonstrated intralesional hemorrhage as early as 12 weeks after inception of cholesterol feeding. Rupture of atherosclerotic plaques is a primary cause of sudden cardiac death in humans (23). Despite the importance of this process, very few animal models are available to study the mechanisms leading to plaque rupture and instability. Recently, however, the BCA in apolipoprotein E-deficient $(24,25)$ and LDLR-deficient mice has been defined as a site prone to plaque instability. In these mice, intralesional hemorrhage frequently is observed at 30-60 weeks of age. Since intralesional hemorrhage most likely can occur only during life, the presence of blood products in the lesion indi-

\section{Figure 5}

Diabetes caused lesion initiation in mice fed a cholesterol-free diet. Diabetic $L D L R^{-/-} ; G P$ mice fed the $0 \%$ cholesterol diet $(\mathbf{A}-\mathbf{F}, \mathbf{H}-\mathbf{I})$ and nondiabetic $L D L R^{-1-} ; G P$ littermates fed the $0 \%$ cholesterol diet ( $G$ and $\mathbf{J}$ ) were perfusion fixed after 12 weeks on diet, as described in Figure 4. The BCA was dissected, paraffin embedded, and serial sectioned until maximal lesion size was identified. Sections were stained using a Movat's pentachrome procedure (A-C, E, and $\mathbf{G})$. Black represents nuclei and elastin, yellow represents collagen and reticular fibers, blue represents glycosaminoglycans, red represents muscle, and intense red represents fibrinoid and fibrin (hemorrhage). Some sections were used to detect macrophages ( $\mathbf{D}$ and $\mathbf{F}$ ), by using a rat monoclonal Mac-2 antibody, and others were used to detect AGEs ( $\mathbf{H}$ and $\mathbf{J}$ ) or used as negative controls (I). Representative sections are shown. Scale bars: $100 \mu \mathrm{m}$. cate that the rupture occurred when the animal was alive. Thus, the occurrence of intralesional hemorrhage in the mouse may be an excellent indicator of plaque instability. However, thrombotic occlusion of vessels is a rare event in mice. Therefore, the mouse seems to be a suitable model for studies of events leading to intralesional hemorrhage as a measure of plaque instability but not for studies of events leading to occlusion $(26,27)$.

Another important difference between mice and humans seems to be that intralesional hemorrhage in the BCA in the mouse most likely occurs primarily as a result of plaque rupture through lateral xanthomas (24), whereas in humans intralesional hemorrhage is believed to occur also as a result of leaky or ruptured microvessels (the vasa vasorum) in the lesion $(28,29)$. In humans, intraplaque hemorrhage is closely associated with lesion instability and plaque progression (29). Repeated intraplaque hemorrhage may contribute to plaque progression and growth (30), and may stimulate macrophage accumulation and cholesterol deposition (29). The increased intralesional hemorrhage and plaque instability in the BCA of diabetic mice is consistent with the higher incidence of thrombus formation (defined as fibrin deposition, intralesional
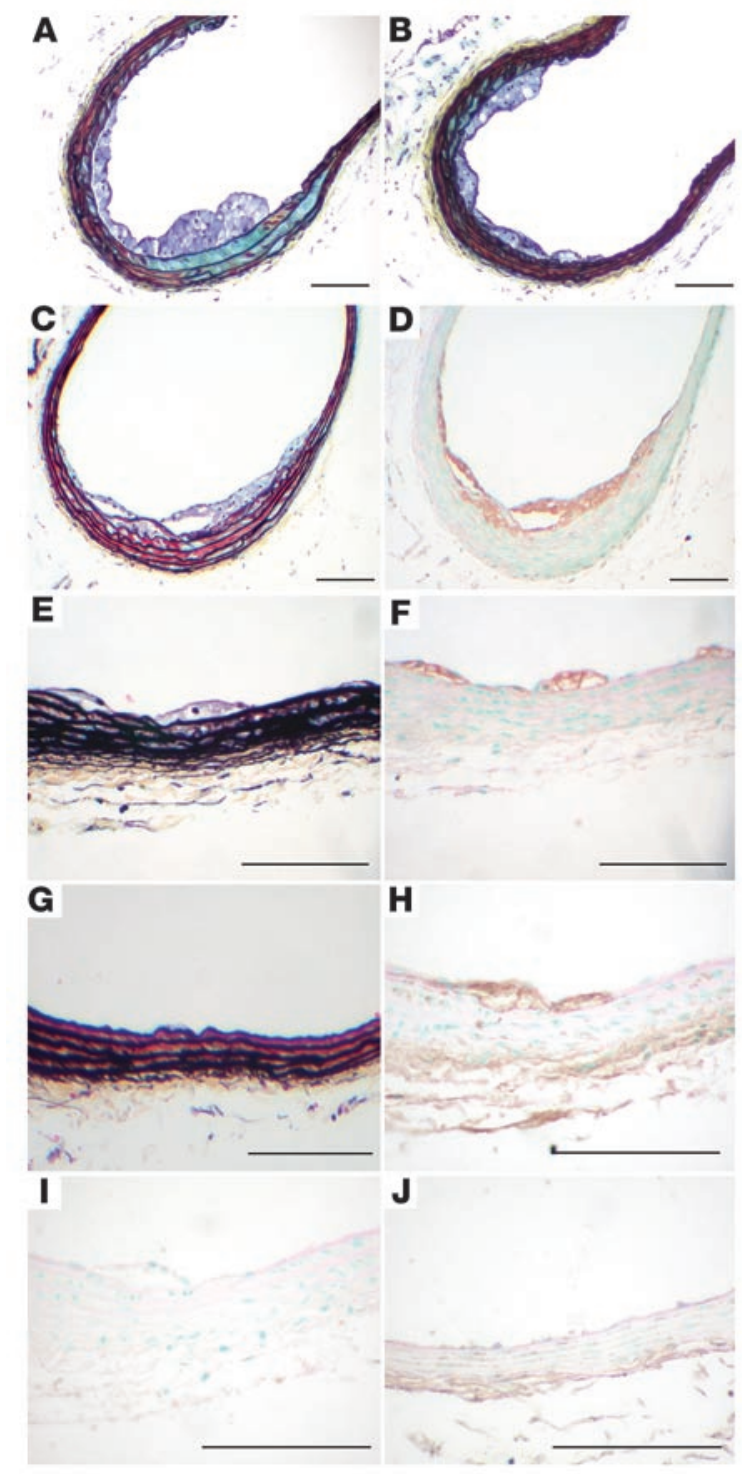

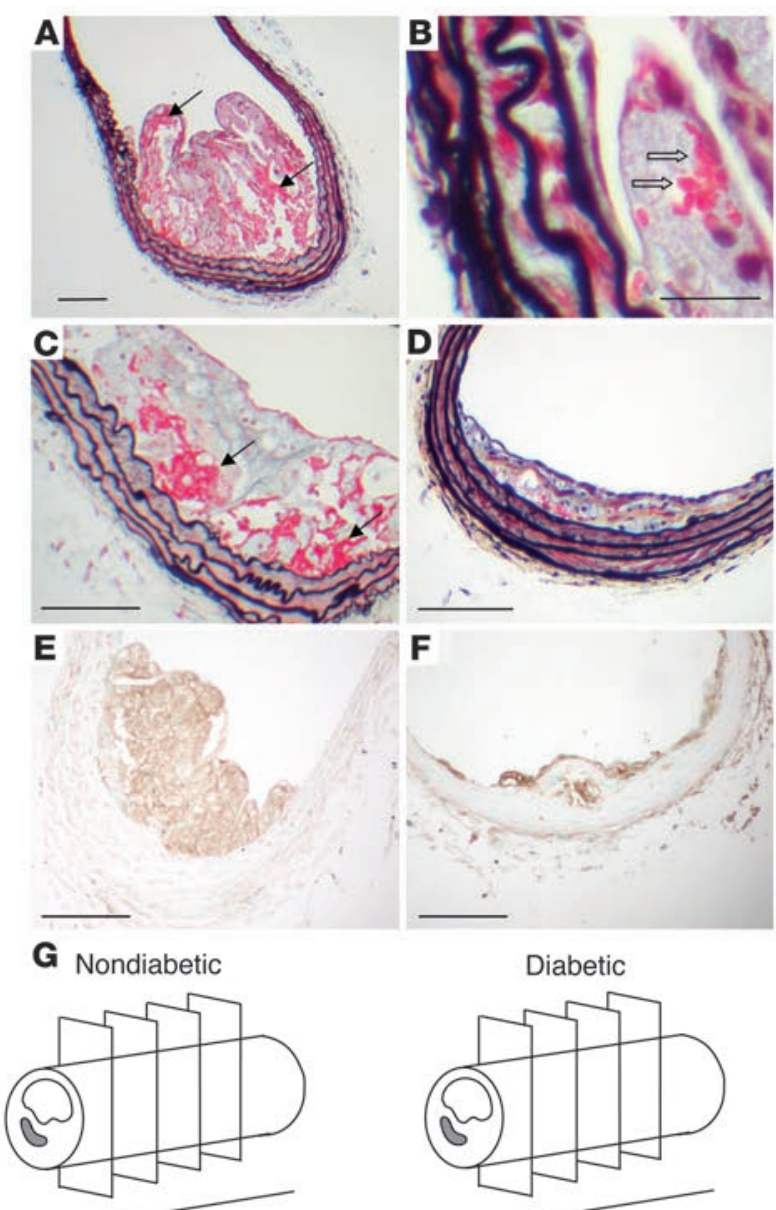

Lesion length analyzed $438 \pm 63 \mu \mathrm{m}$
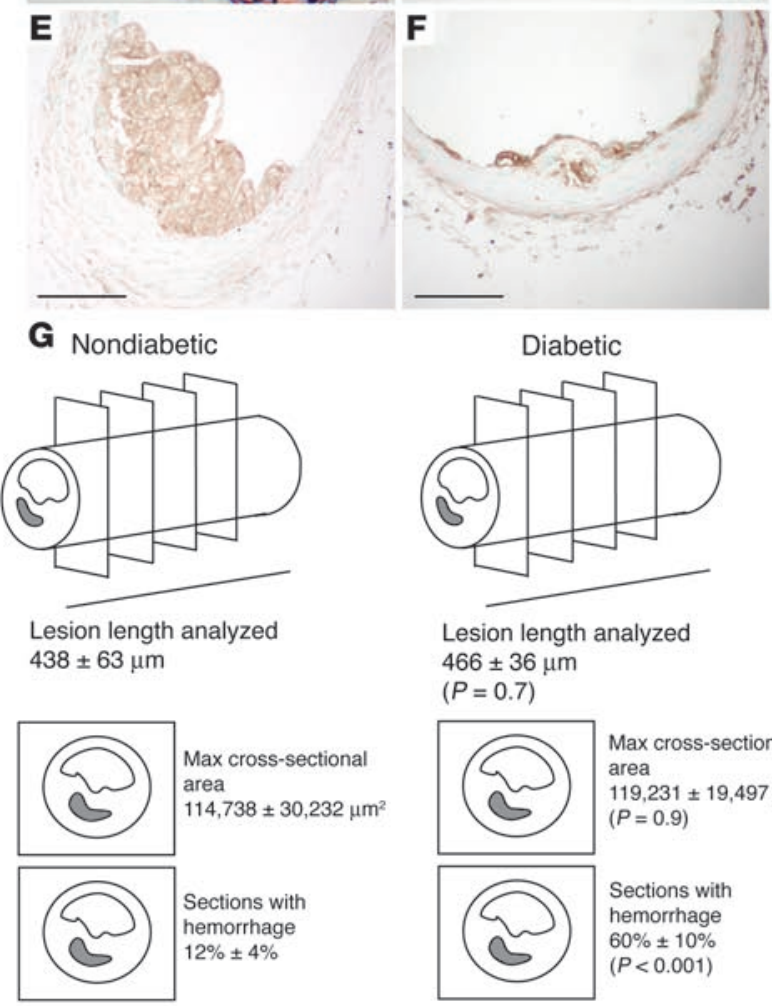

Lesion length analyzed $466 \pm 36 \mu \mathrm{m}$ $(P=0.7)$

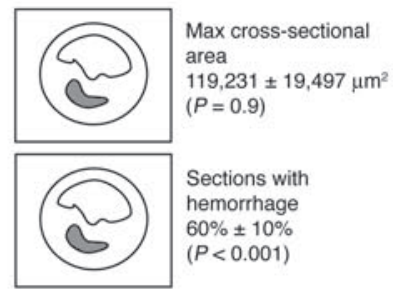

hemorrhage, or both) in coronary lesions from patients with diabetes compared with patients without diabetes (31). The accelerated occurrence of intralesional hemorrhages in diabetic mice was associated with hypercholesterolemia and hypertriglyceridemia, including a marked increase in VLDL levels compared with nondiabetic mice. Although it is most likely that diabetes-associated hyperlipidemia is responsible for the increased intralesional hemorrhage in diabetic mice, it is possible that hyperglycemia also plays a role in this process.

In the $L D L R^{-1-} ; G P$ model, the effects of elevated VLDL and hyperglycemia are separated from those of hyperinsulinemia often present in patients with type 2 diabetes and insulin resistance. The higher frequency of intralesional hemorrhage in diabetic mice fed cholesterol-rich diets supports the hypothesis that diabetic dyslipidemia (characterized mainly by an increased VLDL), which exists

\section{Figure 6}

Diabetes caused advanced lesions in mice fed cholesterol-rich diets. Diabetic $L D L R^{-1-} ; G P$ mice fed the $0.12 \%$ cholesterol diet (A, B, and $\left.\mathbf{E}\right)$, or $0.5 \%$ cholesterol diet $(\mathbf{C})$, and nondiabetic $L D L R^{-1-} ; G P$ littermates fed the $0.12 \%$ cholesterol diet $(\mathbf{F})$ or the $0.5 \%$ cholesterol diet (D) were perfusion fixed after 12 weeks on diet, as described in Figure 4. The BCA was dissected, paraffin embedded, and serial sectioned until maximal lesion size was identified. Sections were stained using a Movat's pentachrome procedure (A-D). Black represents nuclei and elastin, yellow represents collagen and reticular fibers, blue represents glycosaminoglycans, red represents muscle, and intense red represents fibrinoid and fibrin (hemorrhage). Some sections were used to detect AGEs ( $E$ and $\mathbf{F}$ ). Representative sections are shown. Note the intralesional hemorrhage (marked by arrows) in $\mathbf{A}$ and $\mathbf{C}$. In $\mathbf{B}$, erythrocytes in the lesion are indicated by open arrows. Scale bars: $100 \mu \mathrm{m}(\mathbf{A}$, C-F); $20 \mu \mathrm{m}$ (B). (G) A graphical representation of frequency of hemorrhage in lesions of similar size from diabetic and nondiabetic mice.

in both poorly controlled type 1 and type 2 diabetes and correlates with the occurrence of cardiovascular events, is highly atherogenic and may contribute to the increased cardiovascular mortality of diabetic patients $(32,33)$.

In conclusion, we have generated a new animal model of atherosclerosis accelerated by diabetes. This model shows, on the one hand, that diabetes without secondary lipid abnormalities is sufficient to induce lesion initiation and suggests that hyperglycemia accelerates arterial inflammation and lesion initiation. Diabetesinduced increases in triglyceride-rich VLDL, on the other hand, contribute to lesion progression and formation of advanced plaques with intralesional hemorrhage. Thus, hyperglycemia and diabetic dyslipidemia are likely to accelerate different phases of atherogenesis in diabetes.

\section{Methods}

Mice. A transgenic mouse, B6.129-Ldl ${ }^{\mathrm{tm} 1 \mathrm{Hdr}} \mathrm{Tg}$ (Rip-LCMVGP) $1 \mathrm{KBUW}$, was developed by breeding LDLR-deficient mice, tenth-generation backcross into the C57BL/ 6 background (The Jackson Laboratory) with $R I P-L C M V-G P^{+/-}$transgenic mice (C57BL/6 background). The $\mathrm{F}_{1}$ generation $\left(L D L R^{+/-} ; G P^{+/-}\right)$was bred and genotyped, and $L D L R^{-/-}$mice with or without the GP transgene were bred again to generate the $L D L R^{-1-} ; G P^{+}$ mouse. Since there is no difference in the ability of LCMV to induce diabetes in $G P^{+/-}$and $G P^{+/+}$mice, both were used. Mice were housed in a specific pathogen-free, temperature-controlled biosafety-level-3 facility, which maintained a 12-hour light/dark cycle, and were given free access to food and water. Since male $L D L R^{-/-}$mice fed a high-fat diet can develop type 2 diabetes (34), female mice, which do not develop diabetes when fed high-fat diets, were used.

Genotyping. Genotyping was performed by PCR, using tail-tip DNA. For the GP transgene, forward and reverse primers were as follows: GP-T10, 5'TGGACAGGCTCAGATGGCAAGA-3'; GP-T11, 5'-CTCAAAGCAGCCTTGTTGTAGTAGTAGTC-3'. To detect LDLR deficiency, genotyping was performed according to the protocol provided by The Jackson Laboratory.

Study protocol. Female littermate mice received an intraperitoneal injection of saline solution or LCMV $\left(10^{5} \mathrm{PFU}\right)$ at $7-10$ weeks of age. Mice were fed semi-purified diets designed for this study (Harlan Teklad) for 12 weeks, starting when diabetes developed at 1 week after LCMV injection. For control nondiabetic mice, the diets were started 1 week after saline injection. The diets, which contained no cholate or antioxidants, were as similar as possible in terms of calories per gram but contained cholesterol levels ranging from $0 \%$ to $1.25 \%$ (Table 4 ). 

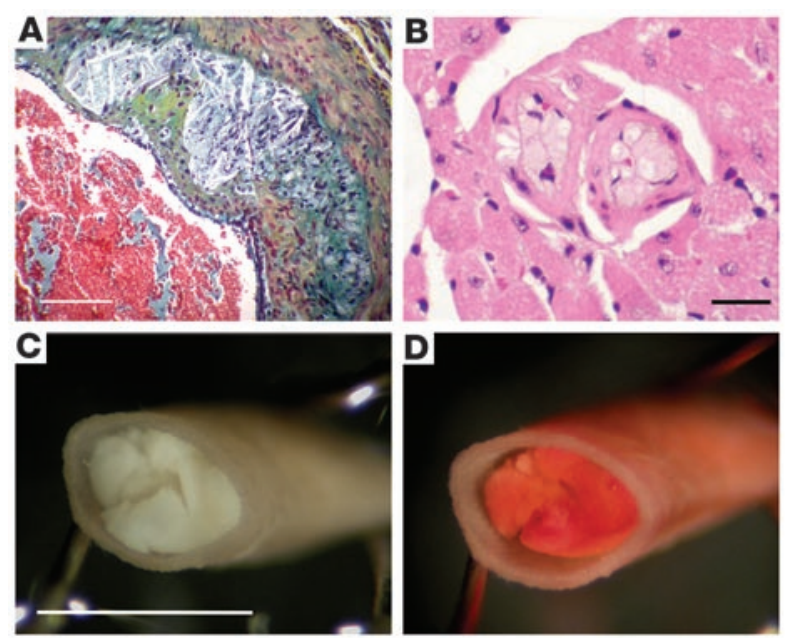

Body weight, urinary glucose, and ketonuria (Ketodiastix; Bayer Corp.), and saphenous vein blood glucose (Precision Q·I·D Complete Blood Glucose Monitoring System; MediSense Inc.) were monitored at least weekly. To avoid weight loss and ketonuria, most diabetic mice received slowrelease insulin ( $0.1 \mathrm{U}$ bovine insulin per day) by subcutaneous implantation of pellets (LinShin Canada Inc.). The pellet was replaced as needed. The severity of diabetes was similar in mice fed the different diets. One group of mice fed the cholesterol-free diet received intense insulin therapy (as much as $0.2 \mathrm{U} /$ day). The study was approved by the University of Washington Animal Care Committee.

Measurements of lipids, lipoprotein profiles, and LDL susceptibility to oxidation. During the study, total cholesterol was measured in blood obtained from the saphenous vein, using a battery-operated reflectance photometer (CardioChek; Polymer Technology Systems Inc.). At the end of the study, blood was collected from the retro-orbital plexus. Plasma total cholesterol and triglycerides were measured by using kits from Diagnostic Chemicals Limited and Sigma-Aldrich, respectively. Plasma levels of NEFAs were measured by using a kit from Wako Chemicals USA Inc.

The cholesterol content of plasma lipoprotein fractions was measured by fast-phase liquid chromatography (FPLC), according to the method of Garber et al. (35). A 100- $\mu$ l aliquot of plasma obtained after 12 weeks on the diet was applied to a Superose 6HR 10/30 column $(10 \mathrm{~mm} \times 300 \mathrm{~mm}$; Amersham Biosciences Corp. $)$, and 250- $\mu \mathrm{l}$ sample fractions were collected for cholesterol analysis.

To study possible compositional differences between LDL particles from nondiabetic and diabetic mice, LDL susceptibility to oxidation was measured in a subgroup of animals, as previously described (36). In short, $\mathrm{LDL}$ (density $=1.019-1.063 \mathrm{~g} / \mathrm{ml}$ ) was isolated from plasma $(400 \mu \mathrm{l})$ of individual mice by density gradient ultracentrifugation. The LDL samples were gently mixed with $5 \mu \mathrm{mol} / \mathrm{l} \mathrm{CuSO}_{4}$. The appearance (lag phase and rate of formation) of conjugated dienes was measured by continuously monitoring absorbance at $234 \mathrm{~nm}$ in a spectrophotometer.

Measurements of insulin and glycated hemoglobin. Free plasma insulin levels were measured to avoid possible interference due to anti-insulin antibodies (37). Briefly, $50 \mu \mathrm{l}$ of plasma were incubated with 25 $\mu$ l polyethylene glycol 6000 for 10 minutes on ice. The samples were centrifuged at $1,600 \mathrm{~g}$ at $4^{\circ} \mathrm{C}$ for 20 minutes, and insulin levels were measured in the supernatant by using an ultrasensitive mouse insulin ELISA kit from ALPCO Diagnostics. This kit cross-reacts with bovine insulin at $80 \%$, and both mouse and bovine insulin stan-

\section{Figure 7}

The combination of diabetes and cholesterol-rich diet caused occlusion of coronary microvessels and lipid embolism. Blocked coronary arteries and lipid embolism probably caused death in diabetic mice fed cholesterol-rich diets. (A) A Movat's stained advanced lesion with cholesterol clefts and fibrous cap in the extension of the aortic sinus into the coronary arteries from a diabetic mouse. This mouse died after 11 weeks on the $0.12 \%$ cholesterol diet. (B) H\&E staining of occluding intramyocardial lesions at the time of death from a diabetic mouse fed the $0.12 \%$ cholesterol diet for 11 weeks. (C) An aorta completely occluded by lipid at the time of death from a diabetic mouse fed the $0.5 \%$ cholesterol diet for 9 weeks. Analysis of cross sections stained with Oil red $\mathrm{O}$ confirmed that the aorta was completely occluded by lipid at a site without a lesion. (D) The same aorta as in $\mathbf{C}$ stained with Sudan IV. Scale bars: $100 \mu \mathrm{m}$ (A); $20 \mu \mathrm{m}$ (B); and $1 \mathrm{~mm}$ (C).

dards were used for comparison. Glycated hemoglobin was measured in red blood cells using a kit (Sigma-Aldrich).

Evaluation of atherosclerosis. After 12 weeks on diet, mice were perfused at constant, near-physiological pressure through the left ventricle with $20 \mathrm{ml}$ of Ringer's solution and then with $15 \mathrm{ml}$ of formal-sucrose (4\% paraformaldehyde, $5 \%$ sucrose, $20 \mu \mathrm{M}$ EDTA, pH 7.4) with outflow through the incised saphenous veins. The aorta was used for en face evaluation of atherosclerotic lesion area, while the BCA, a well-defined artery prone to development of advanced lesions $(24,25)$, was used to study lesion morphology. Aortae were harvested, fixed in formal-sucrose for 24 hours, and then cleaned from adventitia, split longitudinally, and pinned onto black wax, using 0.1-mm-diameter stainless-steel pins (Fine Science Tools Inc.). To visualize atherosclerotic lesions, the aorta was washed rapidly with $70 \%$ ethanol, stained with $0.5 \%$ Sudan IV (Sigma-Aldrich) for 6 minutes, and

\section{Table 4}

Composition of the semipurified diets used in this study

\begin{tabular}{lcccc}
\hline & & & & \\
& Diet 1 & Diet 2 & Diet 3 & Diet 4 \\
& $\mathbf{0 \% ~ c h o l . ~}$ & $\mathbf{0 . 1 2 \%}$ chol. & $\mathbf{0 . 5 \%}$ chol. $\mathbf{1 . 2 5 \%}$ chol. \\
& $\mathbf{( g / k g )}$ & $\mathbf{( g / k g )}$ & $\mathbf{( g / k g )}$ & $\mathbf{( g / k g )}$ \\
Casein & 200.0 & 240.0 & 240.0 & 240.0 \\
DL-Methionine & 3.0 & 3.6 & 3.6 & 3.6 \\
Sucrose & 150.0 & 130.0 & 130.0 & 130.0 \\
Cornstarch & 349.5 & 155.4 & 155.4 & 155.4 \\
Maltodextrin & 150.0 & 150.0 & 150.0 & 150.0 \\
Soybean oil & 30.0 & 30.0 & 30.0 & 30.0 \\
Cocoa butter & 9.0 & 81.0 & 81.0 & 81.0 \\
Anhydrous milkfat & 2.0 & 80.0 & 80.0 & 80.0 \\
Chol. & 0.0 & 1.0 & 4.8 & 12.3 \\
Cellulose & 50.0 & 59.0 & 55.2 & 47.7 \\
Mineral mix (TD94406) & 35.0 & 42.0 & 42.0 & 42.0 \\
CaHPO & 4.0 & 4.8 & 4.8 & 4.8 \\
Vitamin mix (TD94047) & 15.0 & 18.0 & 18.0 & 18.0 \\
Choline bitartrate & 2.5 & 5.2 & 5.2 & 5.2 \\
Macronutrients & & & & \\
$\quad$ Fat (\%) & 10.8 & 40.0 & 40.0 & 40.0 \\
$\quad$ Protein (\%) & 19.7 & 19.6 & 19.6 & 19.6 \\
$\quad$ Carbohydrates (\%) & 69.5 & 40.4 & 40.4 & 40.4 \\
Calories (kcal/g) & 3.62 & 4.35 & 4.35 & 4.35 \\
\hline
\end{tabular}

The diets were produced by Harlan Teklad and were given the numbers TD00241 (diet 1), TD00242 (diet 2), TD00243 (diet 3), and TD00244 (diet 4). 
washed again with $80 \%$ ethanol for 5 minutes. The aorta was covered with PBS and photographed in three segments before and after Sudan IV staining, using a Nikon Coolpix 4500 digital camera (Nikon Inc.). Each picture was analyzed with Adobe Photoshop 6.0 (Adobe Systems Inc.), and the Sudan IV-positive lesion area was quantified using NIH Image software 1.62. All analyses were made in a masked fashion by the same investigator.

Tissue preparation and immunohistochemistry. BCAs and hearts were paraffin embedded and serial sectioned (5- $\mu \mathrm{m}$ sections). The BCA, from the bifurcation off the aortic arch to the branching point to the right subclavian artery and the common carotid artery, is a short artery, and serial sectioning allowed study of the site(s) at which lesions were maximal. Every $20 \mu \mathrm{m}$, two sections were stained using a Movat's pentachrome method (38). Cross-sectional lesion area at the maximal site was quantified using Image Pro-Plus (MediaCybernetics). Lesion morphology was scored in a masked fashion. Macrophages were detected using a rat monoclonal anti-mouse Mac-2 antibody at a final concentration of $10 \mu \mathrm{g} / \mathrm{ml}$ (Cedarlane Laboratories Limited). A rat monoclonal anti-CD8 antibody (BD Biosciences-Pharmingen) or rat IgG (Zymed Laboratories Inc.) at the same concentration was used as negative controls and gave no staining. AGEs were detected by using a rabbit polyclonal anti-AGE antibody at a 1:10,000 dilution provided by Susan Thorpe (University of South Carolina, Columbia, South Carolina, USA). This antibody primarily detects $\mathrm{N}^{\varepsilon}$-(carboxymethyl)lysine (39). Rabbit serum was used as a negative control. In addition, the AGE immunostaining could be blocked by pre-incubation for 1 hour at $37^{\circ} \mathrm{C}$ of the antibody with $1 \%$ AGE-BSA generated as described (40), but not with $1 \%$ control BSA. The reaction was developed by using the streptavidin-HRP complex (Vector Laboratories Inc.) and diaminobenzidine according to a published method (41).

Pancreata were fixed overnight in formal-sucrose. Sections from paraffin-embedded pancreata were immunostained using a monoclonal mouse anti-insulin antibody at a 1:1,000 dilution (Sigma-Aldrich) followed by a biotinylated goat anti-mouse secondary antibody (Vector Laboratories Inc.), and the Vector ABC kit. Adjacent sections were stained with $\mathrm{H} \& \mathrm{E}$.

Statistical analyses. Statistical analyses were performed by two-tailed unpaired Student's $t$ test or one-way ANOVA followed by the NewmanKeuls multiple-comparison test (GraphPad Prism 3.0; GraphPad Soft- ware for Science Inc.). The contributions of different variables to the lesion area were calculated using univariate ANOVA (SPSS 12.0; SPSS Inc.). In Table 3, the results of statistical analyses performed by Fisher's exact test are shown. Levels of significance are denoted by footnotes in the table legend.

\section{Acknowledgments}

We thank Ronald Krofft, Alicia Wiczulis, Maria Baker, Ashley Sherrid, Lucy Suzuki, Shelley Barnhart, and Shari Wang for excellent technical assistance during part of this study; and Åke Lernmark, Renée LeBoeuf, and Stephen Schwartz for fruitful discussions and advice. The Molecular and Genetics Core and the Cytohistochemistry Core of Diabetes Endocrinology Research Center at the University of Washington, funded by a grant from the NIH (P30 DK17047), and the Clinical Nutrition Research Unit at the University of Washington, funded by a grant from the NIH (DK035816), were used for part of the study. We are grateful to the Department of Biostatistics at the University of Washington for help with statistical analysis. This study was supported by NIH grants HL62887 and HL076719; a grant from the Juvenile Diabetes Research Foundation (JDRF); an Innovation Award from the American Diabetes Association (to K.E. Bornfeldt); NIH grants AG04342 PV, DK51091, and a grant from JDRF (to M.G. von Herrath); and NIH grant DK02456 (to A. Chait). N. Lamharzi is supported by the NIH cardiovascular training grant 32HL07820.

Received for publication January 15, 2003, and accepted in revised form June 14, 2004.

Address correspondence to: Karin E. Bornfeldt, Department of Pathology, Box 357470, University of Washington School of Medicine, Seattle, Washington 98195-7470, USA. Phone: (206) 5431681; Fax: (206) 543-3644; E-mail: bornf@u.washington.edu.

C.B. Renard's present address is: INSERM U145, Faculté de Médecine, Nice Cedex 2, France.
1. Kannel, W.B., and McGee, D.L. 1979. Diabetes and cardiovascular disease: The Framingham study. JAMA. 241:2035-2038.

2. The Diabetes Control and Complications Trial Research Group. 1993. The effects of intensive treatment of diabetes on the development and progression of long-term complications of insulin-dependent diabetes mellitus. N. Engl. J. Med. 329:977-986.

3. Oldstone, M.B.A., Nerenberg, M., Southern, P., Price, J., and Lewicki, H. 1991. Virus infection triggers insulin-dependent diabetes mellitus in a transgenic model: role of anti-self (virus) immune response. Cell. 65:319-331.

4. Ohashi, P., et al. 1991. Ablation of tolerance and induction of diabetes by virus infection in viral antigen transgenic mice. Cell. 65:305-310.

5. von Herrath, M.G., Dockter, J., and Oldstone, M.B. 1994. How virus induces a rapid or slow onset insulin-dependent diabetes mellitus in a transgenic model. Immunity. 1:231-242.

6. Ishibashi, S., Goldstein, J.L., Brown, M.S., Herz, J., and Burns, D.K. 1994. Massive xanthomatosis and atherosclerosis in cholesterol-fed low density lipoprotein receptor-negative mice. J. Clin. Invest. 93:1885-1893.

7. Pichler, R.H., et al. 2003. Renal dysfunction in diabetic nephropathy (DN): role of lipids [abstract]. J. Am. Soc. Nephrol. 14:124A.

8. Kunjathoor, V.V., Wilson, D.L., and LeBoeuf, R.C.
1996. Increased atherosclerosis in streptozotocin induced diabetic mice. J. Clin. Invest. 97:1767-1773.

9. Park, L., et al. 1998. Suppression of accelerated diabetic atherosclerosis by the soluble receptor for advanced glycation endproducts. Nat. Med. 4:1025-1031.

10. Keren, P., et al. 2000. Effect of hyperglycemia and hyperlipidemia on atherosclerosis in LDL receptor-deficient mice. Establishment of a combined model and association with heat shock protein 65 immunity. Diabetes. 49:1064-1069.

11. Gerrity, R.G., Natarajan, R., Nadler, J.L., and Kimsey, T. 2001. Diabetes-induced accelerated atherosclerosis in swine. Diabetes. 50:1654-1665.

12. Dixon, J.L., et al. 1999. Dyslipidemia and vascular dysfunction in diabetic pigs fed an atherogenic diet. Arterioscler. Thromb. Vasc. Biol. 19:2981-2992.

13. Reaven, P., Merat, S., Casanada, F., Sutphin, M., and Palinski, W. 1997. Effect of streptozotocin induced hyperglycemia on lipid profiles, formation of advanced glycation endproducts in lesion, and extent of atherosclerosis in LDL-receptordeficient mice. Arterioscler. Thromb. Vasc. Biol. 17:2250-2256.

14. Candido, R., et al. 2004. Irbesartan but not amlodipine suppresses diabetes-associated atherosclerosis. Circulation. 109:1536-1542.

15. Williams, K.J., and Tabas, I. 1998. The response-toretention hypothesis of atherogenesis reinforced. Curr. Opin. Lipidol. 9:471-474.
16. Cuff, C.A., et al. 2001. The adhesion receptor CD44 promotes atherosclerosis by mediating inflammatory cell recruitment and vascular cell activation. J. Clin. Invest. 108:1031-1040. doi:10.1172/ JCI200112455.

17. Schleicher, E.D., Wagner, E., and Nerlich, A.G. 1997. Increased accumulation of the glycoxidation product $\mathrm{N}^{\varepsilon}$-(carboxymethyl)lysine in human tissues in diabetes and aging. J. Clin. Invest. 99:457-468.

18. Horiuchi, S., et al. 1996. Advanced glycation end products and their recognition by macrophage and macrophage-derived cells. Diabetes. 45(Suppl. 3):S73-S76.

19. Ohgami, N., et al. 2001. Cd36, a member of the class b scavenger receptor family, as a receptor for advanced glycation end products. J. Biol. Chem. 276:3195-3202.

20. Januszewski, A.S., Alderson, N.L., Metz, T.O., Thorpe, S.R., and Baynes, J.W. 2003. Role of lipids in chemical modification of proteins and development of complications in diabetes. Biochem. Soc. Trans. 31:1413-1416.

21. Kislinger, T., et al. 2001. Receptor for advanced glycation end products mediates inflammation and enhanced expression of tissue factor in vasculature of diabetic apolipoprotein E-null mice. Arterioscler. Thromb. Vasc. Biol. 21:905-910.

22. Booth, G., Stalker, T.J., Lefer, A.M., and Scalia, R. 2002. Mechanisms of amelioration of glucoseinduced endothelial dysfunction following 
inhibition of protein kinase $\mathrm{C}$ in vivo. Diabetes. 51:1556-1564

23. Virmani, R., Kolodgie, F.D., Burke, A.P., Farb, A., and Schwartz, S.M. 2000. Lessons from sudden coronary death. Arterioscler. Thromb. Vasc. Biol. 20:1262-1275.

24. Rosenfeld, M.E., et al. 2000. Advanced atherosclerotic lesions in the innominate artery of the ApoB knockout mouse. Arterioscler. Thromb. Vasc. Biol. 20:2587-2592.

25. Williams, H., Johnson, J.L., Carson, K.G., and Jackson, C.L. 2002. Characteristics of intact and ruptured atherosclerotic plaques in brachiocephalic arteries of apolipoprotein E knockout mice. Arterioscler. Thromb. Vasc. Biol. 22:788-792.

26. Cullen, P., et al. 2003. Rupture of the atherosclerotic plaque: does a good animal model exist? Arterioscler. Thromb. Vasc. Biol. 23:535-542.

27. Schwartz, S.M., and Bornfeldt, K.E. 2003. How does diabetes accelerate atherosclerotic plaque rupture and arterial occlusion? [review]. Front. Biosci. 8:s1371-s1383.

28. Virmani, R., Narula, J., and Farb, A. 1998. When neoangiogenesis ricochets. Am. Heart J. 136:937-939.

29. Kolodgie, F.D., et al. 2003. Intraplaque hemorrhage and progression of coronary atheroma. N. Engl. J. Med. 349:2316-2325.
30. Zaman, A.G., Helft, G., Worthley, S.G., and Badimon, J.J. 2000. The role of plaque rupture and thrombosis in coronary artery disease. Atherosclerosis. 149:251-266.

31. Moreno, P.R., et al. 2000. Coronary composition and macrophage infiltration in atherectomy specimens from patients with diabetes mellitus. Circulation. 102:2180-2184.

32. Ginsberg, H.N. 1991. Lipoprotein physiology in nondiabetic and diabetic states. Relationship to atherogenesis. Diabetes Care. 14:839-855.

33. Yki-Järvinen, H. 2000. Management of type 2 diabetes mellitus and cardiovascular risk: lessons from intervention trials. Drugs. 60:975-983.

34. Merat, S., Casanada, F., Sutphin, M., Palinski, W. and Reaven, P.D. 1999. Western-type diets induce insulin resistance and hyperinsulinemia in LDL receptor-deficient mice but do not increase aortic atherosclerosis compared with normoinsulinemic mice in which similar plasma cholesterol levels are achieved by a fructose-rich diet. Arterioscler. Thromb. Vasc. Biol. 19:1223-1230.

35. Garber, D.W., Kulkarni, K.R., and Anantharamaiah, G.M. 2000. A sensitive and convenient method for lipoprotein profile analysis of individual mouse plasma samples. J. Lipid Res. 41:1020-1026.

36. Crawford, R.S., Kirk, E.A., Rosenfeld, M.E., LeBoeuf,
R.C., and Chait, A. 1998. Dietary antioxidants inhibit development of fatty streak lesions in the LDL receptor-deficient mouse. Arterioscler. Thromb. Vasc. Biol. 18:1506-1513.

37. Arnqvist, H., Olsson, P.O., and von Schenck, H. 1987. Free and total insulin as determined after precipitation with polyethylene glycol: analytical characteristics and effects of sample handling and storage. Clin. Chem. 33:93-96.

38. Movat, H.Z. 1955. Demonstration of all connective tissue components in a single section. Arch. Pathol. 60:289-295.

39. Reddy, S., Bichler, J., Wells-Knecht, K.J., Thorpe, S.R., and Baynes, J.W. 1995. $\mathrm{N}^{\varepsilon}$-(carboxymethyl)lysine is a dominant advanced glycation end product (AGE) antigen in tissue proteins. Biochemistry. 34:10872-10878.

40. Renard, C.B., Askari, B., Suzuki, L.A., Kramer, F. and Bornfeldt, K.E. 2003. Oleate, not ligands of the receptor for advanced glycation end-products, promotes proliferation of human arterial smooth muscle cells. Diabetologia. 46:1676-1687.

41. Suzuki, L., Poot, M., Gerrity, R.G., and Bornfeldt, K.E. 2001. Diabetes accelerates smooth muscle accumulation in lesions of atherosclerosis: lack of direct growth promoting effects of high glucose levels. Diabetes. 50:851-860. 